\title{
Nosocomial infections in an Iranian educational hospital: an evaluation study of the Iranian nosocomial infection surveillance system
}

\author{
Bagheri Pezhman ${ }^{1,6} \mathbb{D}$, Rezaei Fatemeh ${ }^{1,2,6}$, Roodgari Amir $^{3}$, Rokhsari Mahboobeh ${ }^{4}$ and \\ Fararouei Mohammad ${ }^{5^{*}}$ (I)
}

\begin{abstract}
Background: Nosocomial infection (NI) or cross-infection is a major health problem in hospitals worldwide.

Aim: This study aimed to report the status of NIs and to evaluate the Iranian nosocomial infection surveillance system (INISS) in a teaching hospital in the south of Iran.

Methods: This is a comparative historical study on the records of hospital admitted patients from 2018 to 2019. Data on patients who were diagnosed with NI was extracted from the INISS database. The database includes data on the incidence of different types of NIs in each hospital ward, the patient's infection outcome, the agents involved, and the site of infection.

Results: The results indicated that the rate of $\mathrm{NI}$ (cases of NI/ 100 admissions) in the hospital was \%2.95. The highest rate of NIs was reported from ICUs. Of the infected patients, $45.61 \%$ were female, $98.95 \%$ had underlying diseases, and $30.88 \%$ died due to nosocomial infections. The median (IQR) of the duration of hospital stay among infected patients was 13 (7-18). The most common site of infection was VAE (ventilator-associated events) (39.40\%) and the most common isolated agent, irrespective of the organ involved, was Acinetobacter (spp.) (22.75\%).

Conclusions: We reported ICU and Acinetobacter (spp.) as the most affected ward and most common agent involved in recorded NIs respectively. The rate of $\mathrm{NI}$ in the study hospital was exceptionally low when compared to its counterparts in a few other developed countries. The INISS needs to be further evaluated with regard to the completeness and representativeness of the surveillance system. Also, we need to evaluate the adherence to the INISS guidelines among staff and physicians in reporting the NIs.
\end{abstract}

Keywords: Cross-infection, Nosocomial infection, Infection rate

\section{Introduction}

Nosocomial infection (NI) or hospital-acquired infection is a common problem in hospitals worldwide [1].

*Correspondence: fararooei@gmail.com; fararooei@yahoo.com

${ }^{5}$ HIV/AIDs Research Center, School of Health, Shiraz University of Medical

Sciences, Razi street, Shiraz, Iran

Full list of author information is available at the end of the article
Nosocomial infections cause major health problems including longer hospital stay and higher mortality among affected patients, especially in developing countries [2]. The rate of nosocomial infection is about $5 \%$ to $10 \%$ in industrialized countries, and about $20 \%$ to $25 \%$ in developing countries [3]. According to WHO, the highest rate of nosocomial infections is reported from the Eastern Mediterranean and Southeast Asia, and 
the lowest rate is reported from the Western Pacific, Ocean, and Europe [4]. It is also reported that about 7\% of hospitalized patients in developed and $10 \%$ of them in developing countries acquire NIs [5]. According to several studies from the US, Europe, and Singapore, the incidence of NI varies from 3.2 to $11.9 \%$, depending on the region [6-9]. Nosocomial infections increase hospital costs via longer hospital stay [3]. Also, patients with nosocomial infections can transmit the infection to other patients, increasing the risk of the spread of an invasive type of agent in the community [10]. It is estimated that NIs have imposed a cost of about $\$ 6127.65$ in China in one year [11]. Finally, NIs are highly lethal depending on the characteristics of the infectious agents and the patients.

Despite the fact that NIs are quite common in medical centers, the diagnosis of NIs is not straightforward, as the organisms that are responsible for most nosocomial infections have dramatically changed over the past 30 years $[12,13]$. That is why, despite the major progress in the prevention and treatment of infectious diseases, NIs continue to be the most important causes of mortality and adverse living conditions for millions of patients worldwide [14]. Arbitrary use of antibiotics in hospitals and communities not only causes microbial resistance that makes the treatment of NIs much harder and longer, but also causes many permanent health consequences in the affected patients [15]. As a result, monitoring and preventing NIs are key measures to improve the effectiveness and quality of healthcare. Accordingly, providing accurate and adequate information about NIs is essential in introducing effective prevention programs in hospitals [16]. This study aimed to represent the status of NIs and to evaluate INISS via reporting its main indexes and comparing the calculated NI rate in Ali-Asghar hospital (a referral teaching hospital in Shiraz, Iran) with few other hospitals worldwide.

\section{Methods}

In this study, we analyzed the epidemiological status of nosocomial infections in a referral teaching hospital.

\section{Setting}

Ali-Asghar is a teaching hospital under Shiraz University of Medical Sciences with 200 beds. The hospital is located in the south of Iran and has two intensive care units (ICUs) for internal diseases, one neurology ICU, and two general surgery wards as well as neurology, internal medicine, ophthalmology, gynecology, kidney, reconstructive and cosmetic surgery, ENT, poisoning, and several outpatient clinics. The hospital is a referral center for the above-mentioned specialties in the southern part of the country.

\section{The Iranian nosocomial surveillance system (INISS)}

In each Iranian hospital, NIs are routinely registered with the INISS by a nosocomial infection control nurse who is well trained for monitoring the NI cases. The system was set up by the nosocomial infection care program under the direct supervision of the center for communicable disease control in the Iranian Ministry of Health and Medical Education. The system is used as a core approach for monitoring NIs in all Iranian hospitals. Currently, INISS has been integrated with the national health care program under the Iranian Ministry of Health. At the national level, the program has a technical committee managing the fields of scientific and executive issues, strengthening and expanding cross-sectoral coordination, programming, providing scientific support, and providing/ updating the guidelines [17]. The flowchart presents the workflow of the INISS according to the latest guidelines.

\section{Data collection process}

Data was obtained from both the INISS database and the medical file of patients who were admitted to the hospital within the year preceding the starting time of the study (March 2019). The active lab based case finding is done based on the definitions provided by CDC under the National Healthcare Safety Network (NHSN) office and the national nosocomial infection registration program $[18,19]$. According to the program (Fig. 1), the process of diagnosis and reporting NIs starts with the hospital's infection control nurse collecting daily reports on suspicious cases of NI from the head nurses of all hospital wards based on criteria defined by CDC [20]. Also, the results of all positive microbial cultures or chest radiographies are reported by the supervisor of microbiological laboratory or a radiologist to the infection control nurse who later delivers the reports to the hospital's well trained and experienced infectious disease specialist. The specialist investigates all reported cases and confirms the cases, providing the patients are on or after the 3rd hospital day and meet the predefined CDC's criteria. If the suspicious cases of NI are confirmed by the specialist, the case is reported to the nosocomial infection nurse. Follow-up visits are paid by the infectious disease specialist to manage and monitor the condition in the NI patients from diagnosis to the date that the patient is discharged or dead. The data of the registered NI cases includes age, gender, date of hospitalization, the reason for the admission, date at which the first symptom of the NI was started the ICD code of the NI, the outcome of NI, type 


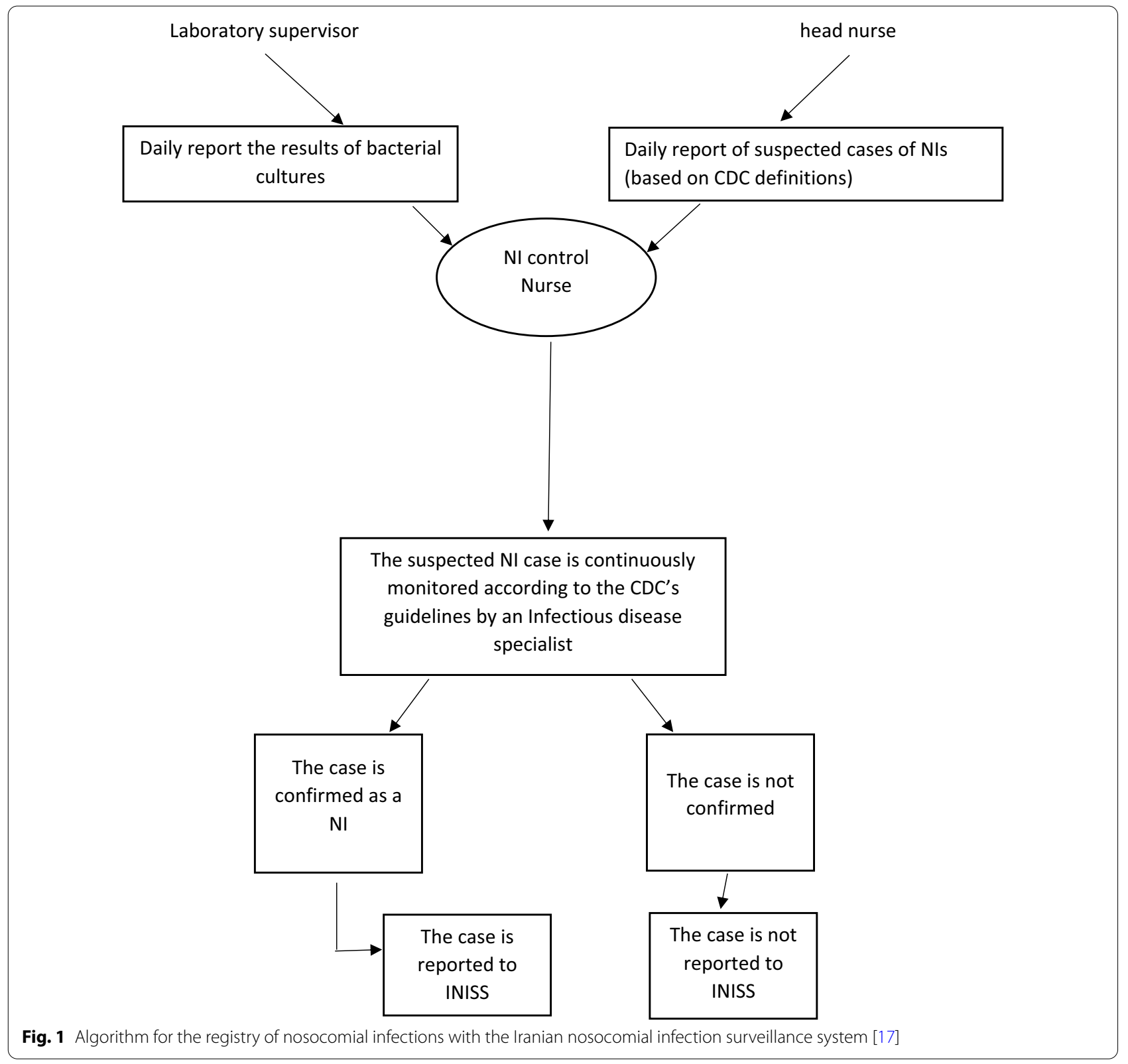

of organism found responsible for the infection, duration of hospital stay, the interval from hospital admission to the NI, hospital ward, the device involved, and the site of infection. To calculate the infection rate (incidence) of NIs, the number of nosocomial infections is divided by the number of admitted patients on a monthly basis [21$24]$. Based on the ICD cods, total number of surgical site infections was divided by the number of registered surgeries conducted during the study period to calculate the surgical site infection rate. No data was available on the number of instrument used. As a result, the instrument specific infection was reported in percent of all instrument related infections.

In our study, the measured infection rate is compared with the corresponding index reported by other recently published studies (the past 10 years). The main criterion for including the articles was applying similar method of calculating the rate of NI among patients admitted to a general hospitals. Accordingly, databases of google scholar, web of science, Scopus, and PubMed were searched with the following search strategy: "infection rate OR incidence rate AND nosocomial infection OR hospital acquired infection" for finding relevant articles 
Table 1 Infection rate of nosocomial infection in different wards

\begin{tabular}{llcl}
\hline Ward & $\begin{array}{l}\text { No of } \\
\text { nosocomial } \\
\text { infections }\end{array}$ & $\begin{array}{l}\text { Total number of } \\
\text { hospitalized patients }\end{array}$ & $\begin{array}{l}\text { NI } \\
\text { Infection } \\
\text { rate (\%) }\end{array}$ \\
\hline $\begin{array}{l}\text { Internal \& Neu- } \\
\text { rology ICUs }\end{array}$ & 204 & 551 & 37.02 \\
$\begin{array}{l}\text { Internal } \\
\text { Neurology }\end{array}$ & 29 & 1601 & 1.81 \\
Surgery & 21 & 1623 & 1.29 \\
CCU & 3 & $3471^{\mathrm{a}}$ & 0.72 \\
Gynecology & 3 & 947 & 0.32 \\
All & 285 & 1477 & 0.20 \\
\hline
\end{tabular}

ICU intensive care unit; CCU critical care unit

${ }^{a}$ Total number of recorded surgeries

published from the year 2010 to 2020 (conducted before COVID-19 pandemic). Among the matched articles, several were excluded because they were conducted on specific types of patients, infections or conditions (e.g. coronavirus pandemic). Finally, 11 articles matched the inclusion criterion and used for the comparison. Median and percentage of numbers are used for descriptive analysis. To conduct the analysis, SPSS version 24 (IBM Corp, Armonk, NY) was used.

\section{Results}

In total, 285 cases of nosocomial infections had been registered to INISS in the hospital from April 2018 to March 2019. The lowest and the highest age of patients who were diagnosed with nosocomial infection were 13 and 99 years respectively (the median (IQR) of patients' age was 68.5 (62-71) years). The annual incidence rate of $\mathrm{NI}$ in the hospital was $\% 2.95$ and the highest NI rate was reported from the internal \& neurology ICUs $(37.02 \%)$ (Table 1). Table 2 presents the relative frequency NIs by sites, sex and duration of hospitalization. Accordingly, the most common sites reported to be involved with NI were ventilator-associated respiratory tract (39.30\%), and UTI (Urinary tract infection) (33\%). Of patients with NI, $30.88 \%$ died due to the infection. Of the reported NI cases, $45.61 \%$ were female and $98.95 \%$ had underlying diseases such as encephalitis, asthma, and diabetes. The median (IQR) of the duration of hospital stay among patients with NI was 13 (7-18) days (Table 2). Irrespective of the organ involved, the most common isolated microorganisms responsible for the NIs were Acinetobacter (spp.) (22.75\%) and Escherichia (E. coli) (11.03\%). However, the types of microorganisms involved in $32.41 \%$ of cases were not defined. Among all instrument related infections, endotracheal tubes (46.41\%), and urinary catheters $(32.49 \%)$ were the two most common devices involved. The rest of devices involved in the NIs were: other devices (13.8\%), temporary central venous catheter $(5.49 \%)$, peripheral venous catheter $(1.69 \%)$,

Table 2 Frequency distribution of nosocomial infections by site, sex as well as duration of hospitalization

\begin{tabular}{|c|c|c|c|c|c|c|c|}
\hline & VAE & PNEU & UTI & BSI & SSI & Other & Total \\
\hline Total number of NIs (\% of all sites) & $112(\% 39.3)$ & $29(\% 10.2)$ & $94(\% 33.0)$ & $36(\% 12.6)$ & $12(\% 4.2)$ & $2(\% 0.7)$ & $285(\% 100.0)$ \\
\hline$\%$ Male & $54(\% 48.21)$ & $20(\% 68.97)$ & $49(\% 52.13)$ & $20(\% 55.56)$ & $9(\% 75.00)$ & $1(\% 50.00)$ & $153(\% 53.68)$ \\
\hline Days of hospitalization Median (IQR) & $19(9-26)$ & $10(8-16)$ & $17(7-21)$ & $12(7-19)$ & $7(4-9)$ & $14(6-17)$ & $13(7-18)$ \\
\hline Years of age Median (IQR) & $45(40-48)$ & $73(69.5-77)$ & $67(61-70)$ & $70(65-74)$ & $69(66-73)$ & $59(54-65)$ & $68.5(62-71)$ \\
\hline
\end{tabular}

VAE ventilator-associated events, PNEU non-ventilator-associated Pneumonia, UTI urinary tract infection, BSI bloodstream infection, SSI surgical site infection

Table 3 Frequency distribution of infections by site and ward

\begin{tabular}{lccccccccc}
\hline Ward & VAE (\%) & PNEU (\%) & UTI (\%) & BSI (\%) & SSI (\%) & Others (\%) & Total (\%) & $\begin{array}{c}\text { Admitted } \\
\text { Infection } \\
\text { rate (\%) }\end{array}$ \\
\hline Internal ICUs & $81(62.8)$ & $2(1.6)$ & $33(25.6)$ & $10(7.8)$ & $2(1.6)$ & $1(0.8)$ & $129(100.0)$ & 439 & 29.38 \\
Neurology ICU & $28(37.3)$ & $11(14.7)$ & $24(32.0)$ & $12(16.0)$ & $0(0.0)$ & $0(0.0)$ & $75(100.0)$ & 384 & 19.53 \\
Surgery & $0(0.0)$ & $1(4.0)$ & $17(68.0)$ & $0(0.0)$ & $7(28.0)$ & $0(0.0)$ & $25(100.0)$ & 3471 & 0.72 \\
Women \& Men ward & $2(6.3)$ & $7(21.9)$ & $10(31.3)$ & $9(28.1)$ & $3(9.4)$ & $1(3.1)$ & $32(100.0)$ & 4624 & 0.69 \\
CCU & $0(0.0)$ & $0(0.0)$ & $2(66.7)$ & $1(33.3)$ & $0(0.0)$ & $0(0.0)$ & $3(100.0)$ & 1363 & 0.22 \\
Neurology & $1(4.8)$ & $8(38.1)$ & $8(38.1)$ & $4(19)$ & $0(0.0)$ & $0(0.0)$ & $21(100.0)$ & 2556 & 0.82 \\
\hline
\end{tabular}


Table 4 Infection rate of nosocomial infection reported by the current study and some other recently published studies

\begin{tabular}{|c|c|c|c|c|c|c|}
\hline Country & Publishing date & $\begin{array}{l}\text { Most common site } \\
\text { involved }\end{array}$ & $\begin{array}{l}\text { Most common agent } \\
\text { involved }\end{array}$ & $\begin{array}{l}\text { Ward with the highest } \\
\text { NI rate }\end{array}$ & $\begin{array}{l}\text { Infection } \\
\text { rate of NI } \\
(\%)\end{array}$ & Definition used \\
\hline $\operatorname{Iran}^{*}$ & 2019 & Respiratory tract & Acinetobacter & $I C U \wedge$ & 2.95 & CDC \\
\hline China [25] & 2018 & Respiratory tract & Pseudomonas aeruginosa & Surgical ward & 7.80 & CDC \\
\hline Greece [33] & 2017 & $\begin{array}{l}\text { Lower respiratory tract } \\
\text { infections }\end{array}$ & Klebsiella & Different hospital wards & $5.2 \%$ & ECDC\# \\
\hline India [26] & 2015 & PNEU & Enterobacteriaceae & $\mathrm{ICU}$ & 11.98 & $\mathrm{CDC}$ \\
\hline China [27] & 2015 & Respiratory tract & Staphylococcus aureus & ICU & 7.57 & CDC \\
\hline India [31] & 2015 & pneumonia & Klebsiella pneumoniae & ICU & 58.86 & CDC \\
\hline Iran [34] & 2015 & Urinary tract infection & Escherichia coli & Different hospital wards & $<2 \%$ & CDC \\
\hline Gabon [29] & 2014 & surgical-site infections & Staphylococcus aureus & Surgical ward & 1.60 & CDC \\
\hline Thailand [32] & 2014 & bacteremia & Acinetobacter & Different hospital wards & 0.3 & Study-based \\
\hline Tunisia [28] & 2014 & PNEU & - & ICU & 30.6 & Study-based \\
\hline India [30] & 2013 & Blood stream infections & Streptococcus pneumonia & ICU & 17.6 & CDC \\
\hline Iran [2] & 2013 & Urinary tract infection & - & Surgical ward & 4.14 & CDC \\
\hline
\end{tabular}

*The current study

$\wedge$ Intensive Care Unit

\# European Centre for Disease Prevention and Control

and arterial catheter $(0.84 \%)$. More information regarding the frequency of infections by site and ward is given in Table 3. Also, as presented in Table 4, the nosocomial infection rates in the Iranian hospitals (including the current study), estimated based on CDC's definitions, are among the lowest when compared with those reported from other countries (Table 4).

\section{Discussion}

Nosocomial infections are the major causes of mortality in hospitalized patients. Effective control of NIs in health and medical centers requires sophisticated knowledge and understanding of the occurrence of the infections and their effective parameters [35]. Nosocomial infections not only cause morbidity and mortality but also impose a high cost to the health system and the affected patients [36-38]. The results of this study indicated that the infection rate of NIs was \%2.95, a rate much lower than the estimates provided by studies from other countries. Based on the results of a meta-analysis in 2014, based on the INISS independent sources of data, the overall estimated incidence of NI in Iran was about 30.4\% [39], a completely different figure compared to what was observed in the current study. Similarly, another systematic review on the studies in Tehran (the capital) in 2017 [40], suggested that the incidence rate of NI was about $21.85 \%$, again a figure much higher than the results of the current study. Despite the fact that a set of public and private and non-Teaching hospitals in Iran were included in the above studies, the figures suggest that the rate of NI in our study hospital is meaningfully lower.
The disparity can suggest a problem in the validity of the reported figures from INISS. However, despite the observed discrepancy, according to the results from the meta-analysis [39], the most common sites of NI were the respiratory tract $(39.4 \%)$, urinary tract $(23.8 \%)$, and bacteremia (21.9\%), a pattern similar to what was observed in the current study. However, based on the results of the other meta-analysis [40], the most common causes of NIs in Tehran's non-teaching hospitals were Klebsiella pneumonia (31.4\%), Escherichia coli (30.9\%), Pseudomonas aeruginosa (26.7\%), and Staphylococcus (23.6\%) [40], a pattern significantly different from what was observed in the current study. In the present study, Acinetobacter and Escherichia coli were the most common microorganisms isolated from the patients. With regard to the NIs reported from the hospital wards, the results of the review [40] suggested that the highest rates of incidence of NIs were reported from ICU, surgical (Gynecology, general and neonatal), and burn units respectively. In the present study, the highest rates of infection were reported in the internal ICU and neurology ICU. The results of other Iranian studies on the epidemiological status of NIs in terms of the wards and the involved infectious agents are relatively similar to the results of the present study [36, 41-43]. Accordingly, the results of the current study and other studies from different parts of the country are different in terms of the agent, and site of NIs. Differences in the environment, building, staff, and patient's underlying diseases and behaviors may, to some extent, explain the observed differences. 
According to the results of the current study, the intensive care unit has the highest rate of NI compared to the other units of the hospital. This finding is consistent with few other studies from different parts of the world [4447]. The high rate of NI and its related deaths among ICU admitted patients are closely related to the clinical status of patients who undergo invasive medical and resuscitate procedures. With regard to the mode of transmission, according to an estimate, $25 \%$ of all hospital infections in ICUs are transmitted via blood and air [48] a pattern relatively different from what was reported by the current study.

In the present study, the most common instruments contributing to NIs were ventilators, endotracheal tubes, and urinary catheters. In a study by Rahmanian, the most common factors contributing to NIs were catheters and surgical wounds [49]. Continuous hygiene monitoring by the infection control nurses may enhance the effect of the cleaning process and reduce the risk of infection transmission [50]. In a study in Tehran [40], the most common agents involved in NIs that were transmitted by the use of different types of catheters were resistant to the commonly available antibiotics. Disinfection and sterilization of medical supplies and equipment are always a big challenge in hospitals and clinics even though they are known as the main vehicles involved in NIs. Putting beside the possibility of lower NIs transmission in Iranian hospitals, the lower reported NI rates of the two Iranian hospitals (including the present study) when compared with the other selected studies may suggest a problem in the completeness of the system. It is also worth noticing that in Iran, a significant number of surgeons used antibiotics as a nosocomial infection preventive measure, an intervention that may significantly reduce the number of NIs.

\section{Conclusion}

The overall findings of the present study indicated that the incidence, etiology, and causes of nosocomial infections in the studied educational hospital are significantly different when compared to those reported from other hospitals. Using data from INISS, the rate of NI in the study hospital was exceptionally lower than its counterparts in Iran and some other countries, which used sources of data other than INISS. Also, we noticed a significant discrepancy between the agents involved in NIs when compared to hospitals in other countries. The INISS needs to be further evaluated regarding completeness and representativeness. Also, adherence to the guidelines among staff and physicians in reporting the NIs as well as the effect of structural and instrumental factors on the diagnosis of NIs may explain the observed pattern. It seems that interventions including supervising staffs regarding their adherence to the defined guidelines and more physicians and nurses training with regard to the diagnosis and reporting nosocomial infections are suggested [51].

\section{Limitations}

No follow-up was made to the patients after discharge. This causes a possibly significant underestimation of the incidence of NIs. We could not calculate the device associated infection rate due to not having the data on devices usage by admitted patients.

\section{Acknowledgements}

The authors dedicated their sincere appreciation to Ali-Asghar hospital chief and infection control unit personnel in Shiraz University of Medical Sciences (SUMS) for their cooperation and contribution.

\section{Authors' contributions}

PB analyzed and interpreted the patient data. FR was a major contributor in writing the manuscript. AR and MR helped researchers with data gathering in the hospital and MF was a major supervisor in all processes as well as interpretation of results. All authors read and approved the final manuscript.

\section{Funding}

This study was financially supported by the Vice-Chancellor for Research and Technology of Shiraz University of Medical Sciences (SUMS), which is worthy of thanks and appreciation.

\section{Availability of data and materials}

The datasets used and/or analyzed during the current study are available from the corresponding author on reasonable request.

\section{Declarations}

\section{Ethics approval and consent to participate}

The study protocol was reviewed and approved by the ethical committee of Shiraz University of Medical Sciences (approved No =21896). All methods were carried out in accordance with relevant guidelines and regulations. The selected hospital was a teaching hospital and at the time of admission, informed consent was obtained from all participants and if participants are under 16 or dead, from a parent and/or legal guardian.

\section{Consent for publication \\ Not applicable.}

\section{Competing interests}

The authors declare that they have no competing interests.

\section{Author details}

${ }^{1}$ Student Research Committee, Shiraz University of Medical Sciences, Shiraz, Iran. ${ }^{2}$ Department of Social Medicine, Jahrom University of Medical Sciences, Jahrom, Iran. ${ }^{3}$ Division of Infectious Disease, Department of Internal Medicine, Shiraz University of Medical Sciences, Shiraz, Iran. ${ }^{4}$ Ali-Asghar Educational Hospital, Shiraz University of Medical Sciences, Shiraz, Iran. ${ }^{5}$ HIV/AIDs Research Center, School of Health, Shiraz University of Medical Sciences, Razi street, Shiraz, Iran. ${ }^{6}$ Non-communicable diseases Research Center, Fasa University of Medical Sciences, Fasa, Iran.

Received: 7 April 2021 Accepted: 6 December 2021

Published online: 15 December 2021 


\section{References}

1. Ahoyo TA, Bankolé HS, Adéoti FM, Gbohoun AA, Assavèdo S, AmoussouGuénou $\mathrm{M}$, et al. Prevalence of nosocomial infections and anti-infective therapy in Benin: results of the first nationwide survey in 2012. Antimicrob Resist Infect Control. 2014:3 (1):17.

2. Askarian M, Mahmoudi $\mathrm{H}$, Assadian O. Incidence of nosocomial infections in a big university affiliated hospital in Shiraz, Iran: a six-month experience. Int J Prev Med. 2013;4 (3):366.

3. LiY, Gong Z, LuY, Hu G, Cai R, Chen Z. Impact of nosocomial infections surveillance on nosocomial infection rates: a systematic review. Int J Surg. 2017:42:164-9.

4. Alten JA, Rahman AKMF, Zaccagni HJ, Shin A, Cooper DS, Blinder JJ, et al. The epidemiology of healthcare-associated infections in pediatric cardiac Intensive Care Units. Pediatr Infect Dis J. 2018;37 (8):768-72.

5. Danasekaran R, Mani G, Annadurai K. Prevention of healthcare-associated infections: protecting patients, saving lives. 2017;1 (1):2.

6. Magill SS, Edwards JR, Bamberg W, Beldavs ZG, Dumyati G, Kainer MA, et al. Multistate point-prevalence survey of health care-associated infections. N Engl J Med. 2014;370 (13):1198-208.

7. Magill SS, O'Leary E, Janelle SJ, Thompson DL, Dumyati G, Nadle J, et al. Changes in prevalence of health care-associated infections in US Hospitals. N Engl J Med. 2018;379 (18):1732-44.

8. Cai Y, Venkatachalam I, Tee NW, Tan TY, Kurup A, Wong SY, et al. Prevalence of healthcare-associated infections and antimicrobial use among adult inpatients in Singapore Acute-Care Hospitals: results from the first national point prevalence survey. Clin Infect Dis. 2017;64:S61-7.

9. Suetens C, Latour K, Kärki T, Ricchizzi E, Kinross P, Moro ML, et al. Prevalence of healthcare-associated infections, estimated incidence and composite antimicrobial resistance index in acute care hospitals and long-term care facilities: results from two European point prevalence surveys, 2016 to 2017. Eurosurveillance. 2018;23 (46):1800516.

10. Zhang Y, Du M, Chang Y, Chen L-A, Zhang Q. Incidence, clinical characteristics, and outcomes of nosocomial Enterococcus spp. bloodstream infections in a tertiary-care hospital in Beijing, China: a four-year retrospective study. Antimicrob Resist Infect Control. 2017;6 (1):73.

11. Jia H, Li W, Hou T, Ma H, Yang Y, Wu A, et al. The attributable direct medical cost of healthcare associated infection caused by multidrug resistance organisms in 68 hospitals of China. Biomed Res Int. 2019:2019:7634528.

12. Mohammadimehr M, Feizabadi MM, Bahadori O, Motshaker Arani M, Khosravi M. Study of prevalence of Gram-negative bacteria caused nosocomial infections in ICU in Besat hospital in Tehran and detection of their antibiotic resistance pattern-year 2007. Iran J Med Microbiol. 2009;3 (2):47-54.

13. Hajjar J, Savey A, Pinzaru G, Coiron M. Réseau ISO Sud-Est: un an de surveillance des infections du site opératoire. Bulletin Epidemiologique Hebdomadaire. 1996;42:183-5.

14. McBryde E, Bradley L, Whitby M, McElwain D. An investigation of contact transmission of methicillin-resistant Staphylococcus aureus. J Hosp Infect. 2004;58 (2):104-8.

15. Khodare A, Kale P, Pindi G, Joy L, Khillan V. Incidence, microbiological profile, and impact of preventive measures on central line-associated bloodstream infection in liver care intensive care unit. Indian J Crit Care Med. 2020:24 (1):17-22

16. Osman S, Al Talhi YM, AIDabbagh M, Baksh M, Osman M, Azzam M. The incidence of ventilator-associated pneumonia (VAP) in a tertiary-care center: comparison between pre- and post-VAP prevention bundle. J Infect Public Health. 2020;13 (4):552-7.

17. Eybpoosh S, Eshrati B. Nosocomial infection surveillance system in Iran: structures, processes and achievements. Iran J Epidemiol. 2019;15 (1):105-15.

18. Edmond MB, Beekmann SE, Henderson DK, Klompas M, Hooton T. Nosocomial infections. In: Bennett J, Dolin R, Blaster MJ, editors. Mandell, Douglas, and Bennett's principles and practice of infectious diseases. Philadelphia: Elsevier; 2015. p. 3286-346.

19. Masoumi-Asl HZS, Majid-Pour A, Nateghian A, Afhami S, Rahbar S, et al. National guideline on nosocomial infection surveillance system. Tehran: Ministry of Health and Medical Education; 2006.

20. Horan TC, Andrus M, Dudeck MA. CDC/NHSN surveillance definition of health care-associated infection and criteria for specific types of infections in the acute care setting. Am J Infect Control. 2008;36 (5):309-32.
21. Elliott C, Justiz-Vaillant A. Nosocomial infections: a 360-degree review. Int Biol Biomed J. 2018;4 (2):72-81.

22. Haley RW, Culver DH, White JW, Morgan WM, Emori TG. The nationwide nosocomial infection rate. A new need for vital statistics. Am J Epidemiol. 1985;121 (2):159-67.

23. Liu H, Zhao J, Xing Y, Li M, Du M, Suo J, et al. Nosocomial infection in adult admissions with hematological malignancies originating from different lineages: a prospective observational study. PLoS ONE. 2014;9 (11):e113506.

24. Chandrasekar PH, Kruse JA, Mathews MF. Nosocomial infection among patients in different types of intensive care units at a city hospital. Crit Care Med. 1986;14 (5):508-10.

25. Jiang WL, Hu XP, Hu ZP, Tang Z, Wu HB, Chen LH, et al. Morbidity and mortality of nosocomial infection after cardiovascular surgery: a report of 1606 cases. Current Med Sci. 2018;38 (2):329-35.

26. Dasgupta S, Das S, Chawan N, Hazra A. Nosocomial infections in the intensive care unit: incidence, risk factors, outcome and associated pathogens in a public tertiary teaching hospital of Eastern India. Indian J Crit Care Med. 2015;19:14-20

27. Wang L, Zhou K-H, Chen W, Yu Y, Feng S-F. Epidemiology and risk factors for nosocomial infection in the respiratory intensive care unit of a teaching hospital in China: a prospective surveillance during 2013 and 2015. BMC Infect Dis. 2019;19 (1):145.

28. Merzougui L, Barhoumi T, Guizani T, Barhoumi H, Hannachi H, Turki E, et al. Nosocomial infections in the Intensive Care Unit: annual incidence rate and clinical aspects. Pan Afr Med J. 2018;30:143.

29. Scherbaum M, Kösters K, Mürbeth RE, Ngoa UA, Kremsner PG, Lell B, et al. Incidence, pathogens and resistance patterns of nosocomial infections at a rural hospital in Gabon. BMC Infect Dis. 2014;14 (1):124.

30. Singh S, Chaturvedi R, Garg SM, Datta R, Kumar A. Incidence of healthcare associated infection in the surgical ICU of a tertiary care hospital. Med J Armed Forces India. 2013;69 (2):124-9.

31. Choudhuri AH, Chakravarty M, Uppal R. Epidemiology and characteristics of nosocomial infections in critically ill patients in a tertiary care Intensive Care Unit of Northern India. Saudi J Anaesth. 2017;11 (4):402-7.

32. Hongsuwan $M$, Srisamang $P$, Kanoksil M, Luangasanatip $N$, Jatapai A, Day $N P$, et al. Increasing incidence of hospital-acquired and healthcare-associated bacteremia in Northeast Thailand: a multicenter surveillance study. PLoS ONE. 2014;9 (10):e109324.

33. Kritsotakis El, Kontopidou F, Astrinaki E, Roumbelaki M, loannidou E, Gikas A. Prevalence, incidence burden, and clinical impact of healthcareassociated infections and antimicrobial resistance: a national prevalent cohort study in acute care hospitals in Greece. Infect Drug Resist. 2017;10:317-28.

34. Saeidimehr S, Geravandi S, Rahim F, Yousefi F, Salmanzadeh S, Mohammadi MJ, et al. Nosocomial infection rates during one year in Naft Grand Hospital, Ahvaz. Iran Jundishapur J Health Sci. 2015:7 (4):1-5.

35. Horan T. Surveillance of nosocomial infections. Hosp Epidemiol Infect Control. 2004:22:1659-702.

36. Yazdani Cherati J, Shojaee J, Chaharkameh A, Rezai MS, Khosravi F, Rezai F, et al. Incidence of nosocomial infection in selected cities according NISS software in Mazandaran Province. J Mazandaran Univ Med Sci. 2015;24 (122):64-72.

37. Irek EO, Amupitan AA, Obadare TO, Aboderin AO. A systematic review of healthcare-associated infections in Africa: an antimicrobial resistance perspective. Afr J Lab Med. 2018;7 (2):796.

38. Rajabi M, Abdar ME, Rafiei H, Aflatoonia MR, Abdar ZE. Nosocomial infections and epidemiology of antibiotic resistance in teaching hospitals in South East of Iran. Glob J Health Sci. 2015;8 (2):190-7.

39. Bagheri P, Sepand MR. the review systematic and meta analysis of prevalence and causes of nosocomial infection in Iran. Iran J Med Microbiol. 2015;8 (4):1-12.

40. Mossaddeghrad AM, Esfahani P, Afshari M. Rate and causes of nosocomia infection in Tehran hospitals: a systematic review and meta-analysis of the past 18 years. 5th Iranian Congress of Medical Bacteriology; 2018; Tehran.

41. Hussain Rezaee H, Borji E, Mirzadi I, Salehi A, Sivandipur H, Nekhei M, et al. A study on the rate and the types of hospital infection in the trauma ICU Departments of Kerman Hospitals in the first half of 1393. J Iran Soc Anaesthesiol Intensive Care. 2015:37:91. 
42. Akbari M, Nejad Rahim R, Azimpour A, Bernousi I, Ghahremanlu H. A survey of nosocomial infections in Intensive Care Units in an Imam Reza Hospital to provide appropriate preventive guides based on international standards. Stud Med Sci. 2013;23 (6):591-6.

43. Ghanbari F, Ghajavand H, Behshod P, Ghanbari N, Khademi F. Prevalence of hospital-acquired infections in hospitalized patients in different wards of Shariati Hospital of Isfahan, 2014. J Health. 2018;8 (5):511-7.

44. Shakib P, Lavakhamseh H, Mohammadi B. The prevalence of nosocomial infection in ICU, Besat Hospital, Sanandaj City, Iran. Zanko J Med Sci. 2014;15:45.

45. Dasgupta S, Das S, Chawan NS, Hazra A. Nosocomial infections in the intensive care unit: Incidence, risk factors, outcome and associated pathogens in a public tertiary teaching hospital of Eastern India. Indian J Crit Care Med. 2015;19 (1):14-20.

46. Esfahani BN, Basiri R, Mirhosseini SMM, Moghim S, Dolatkhah S. Nosocomial infections in Intensive Care Unit: pattern of antibiotic-resistance in Iranian Community. Adv Biomed Res. 2017;6:54.

47. Majumdar SS, Padiglione AA. Nosocomial infections in the intensive care unit. Anaesth Intensive Care Med. 2012;13 (5):204-8.

48. Ghiasvandian S. Nosocomial infection in the Intensive Care Unit. HAYAT. 2002;8 (1):27-34.

49. Rahmanian V, Shakeri H, Shakeri M, Rahmanian K, Rahimi M. Epidemiology of nosocomial infections in patients admitted in hospitals Jahrom. Pars Jahrom Univ Med Sci. 2017;15 (1):57-66.

50. Ghodatolah K, Mohammad K, Fereshteh Rasuli R, Zahrasadat E. Evaluating the effect of hospital medical instruments on the nosocomial infection risk. J Urmia Nurs Midwifery Faculty. 2015;13 (7):579-87.

51. Jeihooni AK, Kashfi SH, Bahmandost M, Afzali Harsini P. Promoting preventive behaviors of nosocomial infections in nurses: the effect of an educational program based on health belief model. Investigacion y educacion en enfermeria. 2018;36 (1):e09.

\section{Publisher's Note}

Springer Nature remains neutral with regard to jurisdictional claims in published maps and institutional affiliations.

- fast, convenient online submission

- thorough peer review by experienced researchers in your field

- rapid publication on acceptance

- support for research data, including large and complex data types

- gold Open Access which fosters wider collaboration and increased citations

- maximum visibility for your research: over $100 \mathrm{M}$ website views per year

At BMC, research is always in progress.

Learn more biomedcentral.com/submissions 